\title{
Performance Assessment of Series Power Electronic Compensator in a Real LV Network
}

\author{
E. Kazemi-Robati, M. S. Sepasian \\ Department of Electrical Engineering, \\ Shahid Beheshti University, Tehran, Iran \\ e_kazemi@sbu.ac.ir
}

\begin{abstract}
Due to the requirement of higher Power Quality (PQ) levels in modern distribution systems and the higher load demand in the grids, certain topologies of Power Electronic Compensators (PECs) can be added to LV networks by the Distributer System Operator (DSO) to satisfy the request of the customers. Among the available solutions introduced in the previous studies, the Series PEC (SPEC) can provide the voltage improvement more effectively. In this paper, the performance of the SPEC is investigated in voltage profile improvement of a real LV network with real measured data. Accordingly, the whole-year collected data of meters in a city in the north of Italy is used in the assessment of the voltage of the $\mathrm{LV}$ distribution feeder. By a preliminary analysis to the grid, the severity and duration of voltage variations are determined during the year. Then the SPEC is added to the grid to stabilize the supply voltage of the substation bus using only reactive power. Accordingly, the grid assessment is repeated for the whole year in the presence of the device. Moreover, the assessment is accomplished with respect to different set points of the SPEC and the device performance is investigated. By an analysis of the results of the simulations, the capability of the device in reducing the voltage variations is studied with respect to the SPEC limits.
\end{abstract}

Index Terms--SPEC, power quality, LV networks, Open-UPQC, voltage variation.

\section{INTRODUCTION}

The existing electricity network needs to change into an efficient, reliable, intelligent electrical system, because new elements of the modern distribution system, such as Distributed Generation (DG) units, may lead to more complicated conditions in voltage management of these future smart grid systems[1-3]. Moreover, in future, the increment of load level of the grids will introduce more complicated and severe voltage problems in the grid [4,5]. Accordingly, there is a trend by the Distribution System Operators (DSOs) to implement applicable solutions in the grid to solve the voltage deviation problems and provide the PQ requested by the end-users.

In particular, it is complicated for the DSO to provide the RMS voltage standards when high penetration of DG is reached in the grid. Indeed, nowadays, the main solution used to solve long duration voltage drifts are the smart distribution transformers, hybrid transformers and solid-state transformers. These voltage conditioners are mainly used in

\author{
K. Akkala, R. Faranda \\ Department of Energy, \\ Politecnico di Milano, Via La Masa 34, 20156, Milano, Italy \\ roberto.faranda@polimi.it
}

$\mathrm{HV}$ and MV network. But more often in LV networks, voltage deviation problems can be solved only increasing the section of the cables or changing the network configuration.

In the modern LV grids, due to the continuous changes in both load demand and DG power levels, the method incorporated for solving the voltage problems should have the ability to track the deviations and apply the modifications to the control action. In this context, only electronic compensator devices can be used. Unified Power Quality Conditioner (UPQC) [6,7], Open UPQC [8-10], Dynamic Voltage Compensator (DVC) and Series Power Electronic Compensator (SPEC) [11,12], can perfectly cover these long-term events. They have the ability to operate continuously in order to regulate voltage at the point of common coupling (PCC) and protect a group of downstream end users from several voltage disturbances.

A very cheap and applicable solution to solve this problem in LV electrical grids is the SPEC. Some topologies and control systems can be found in previously published papers [12-15]. In order to compensate long voltage variations in LV networks within $10 \%$ of nominal value, the SPEC provides only non-active power. Indeed, in steady state condition, it injects a voltage in quadrature to the line current. So it needs a very small storage system to compensate fast transient variations.

In order to provide a sense to the ability of the SPEC in voltage profile enhancement in real cases, the SPEC is ideally added to a real LV network (sited in a city in the north of Italy) to monitor the end-users voltage deviation in presence of the device. The SPEC is added to the substation of the grid and the whole-year voltage assessment is accomplished in the presence of the device.

According to the real measurements, the studied grid is working without any problem during the whole year both with and without the SPEC. In order to apply further assessment, the voltage set-point of the SPEC is changed and the grid is studied with respect to the new settings. Finally, the losses of the network are evaluated in all studied cases, the working limits of the SPEC are taken into account and the ability of the device for providing the constant voltage in the PCC is studied.

The paper is organized as follows. The SPEC working principles and limits in LV grid power quality improvement is briefly described in Section II. The complete assessment of 
the main grid is given in Section III. The effect of adding the SPEC to the grid is investigated in Section IV and the paper is finally concluded in Section V.

\section{SPEC WORKING PRINCIPLE}

The topology of the SPEC connected to the substation of an LV network is given in Fig. 1 [12]. The device is connected in series with the line to provide a constant voltage at PCC of the network which was facing both voltage deviations in the substation and the load-changes in the grid.

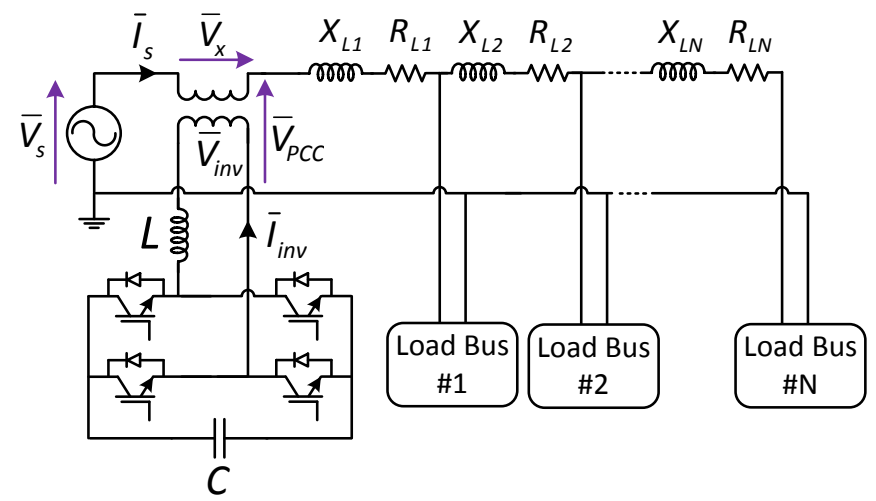

Fig. 1. Diagram of the SPEC unit in a multi-bus LV network

According to Fig. 1, the KVL equation (1) can be written.

$\bar{V}_{P C C}=\bar{V}_{s}+\bar{V}_{x}$

In the equation, $\bar{V}_{P C C}$ is the voltage at the PCC, $\bar{V}_{s}$ is the voltage at the output of MV/LV substation transformer and $\bar{V}_{x}$ is the SPEC injected voltage. In steady state, $\bar{V}_{x}$ is always perpendicular to the line current $\bar{I}_{S}$ to provide the injected voltage by a pure reactive power exchange with the grid.

Even if the line current $\bar{I}_{S}$ changes in function of the load (absorbed or injected and in lead or in lag) due to the different working conditions happening in the grid, the working principle of the SPEC is similar in all cases. Therefore, it would be enough to analyze one of these conditions to evaluate the SPEC limitations.

Accordingly, the working principle of the device for over-voltage and under-voltage conditions when the line current $\bar{I}_{S}$ is absorbed in lag is presented in Fig. 2 [12].

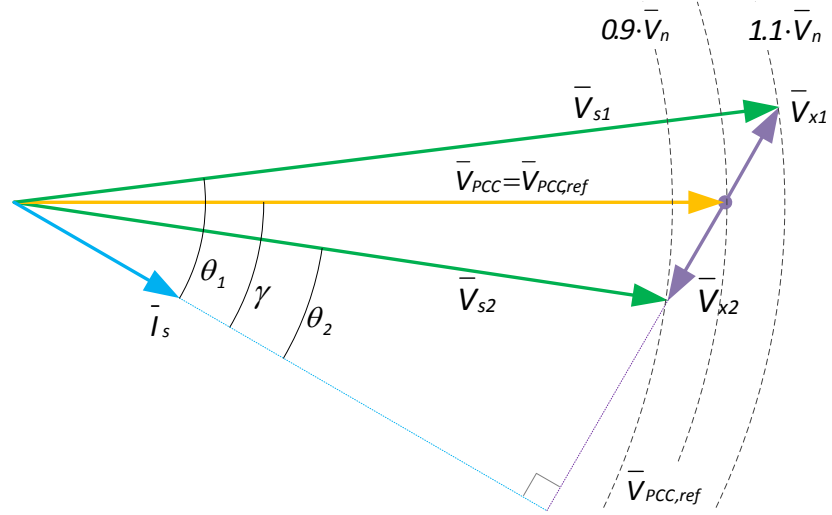

Fig. 2. Working principle of the SPEC

In this figure, $\left\{\bar{V}_{x 1}, \bar{V}_{x 2}\right\}$ are the injected voltage of the SPEC and $\left\{\bar{V}_{s 1}, \bar{V}_{s 2}\right\}$ are the voltage at the output of MV/LV substation transformer point in case of over-voltage and under-voltage, respectively, $\bar{V}_{P C C, \text { ref }}$ is the pre-set voltage of the PCC and $\bar{I}_{S}$ is the line current.

Hence, the injected voltage of the series unit $V_{x i}$ can be calculated using equation (2).

$V_{x i}=V_{P C C, \text { ref }} \cdot \sin (\gamma)-V_{s} \cdot \sin \left(\theta_{i}\right)$

Accordingly, by injecting the calculated voltage, the SPEC could provide a constant voltage $\bar{V}_{P C C}$ at the PCC point regardless of the voltage $\bar{V}_{s}$. It should be noted that there could be deviations in PCC voltages in presence of the SPEC in real-world applications due to the limits of the SPEC $[10,12]$ and the dynamics of both substation voltage and load current. With a constant set-point for the SPEC, the maximum voltage values which can be compensated is defined with equation (3) [12].

$$
\sqrt{\left|\mathrm{V}_{\mathrm{s}, \max }\right|=} \sqrt{\left|V_{P C C, \text { ref }} \cdot \sin (\gamma)+V_{x, \max }\right|^{2}+\left|V_{P C C, \text { ref }} \cdot \cos (\gamma)\right|^{2}}
$$

While, with the same constant set-point for the SPEC, to evaluate the minimum voltage values which can be compensated it is necessary to evaluate the maximum of equations (4) and (5).

$$
\begin{aligned}
& \left|V_{s, \text { min-a }}\right|= \\
& \quad \sqrt{\left|V_{P C C, \text { ref }} \cdot \sin (\gamma)-V_{x, \max }\right|^{2}+\left|V_{P C C, \text { ref }} \cdot \cos (\gamma)\right|^{2}} \\
& \left|V_{s, \text { min-b }}\right|=\left|V_{P C C, \text { ref }} \cdot \cos (\gamma)\right|
\end{aligned}
$$

When $V_{x, \max }<V_{P C C, r e f} \cdot \sin (\gamma)$, the minimum limit is calculated using (4); otherwise (5) is implemented in the minimum voltage calculation. According to the equations, it is clear that the compensation capability of the SPEC is a function of $V_{x, \max }$ and $\gamma$. For a specified SPEC, the $V_{x, \max }$ is constant and the compensation capability can be improved only by changing the line current angle. These limits are fundamental to discover the SPEC compensation capability limitations.

\section{DESCRIPTION OF THE STUDIED LV NETWORK}

In order to investigate the effect of SPEC, a real LV grid is considered with respect to the recorded data of measurement systems during a whole year. The meters measure active power, reactive power and the magnitude of voltage and current in some nodes.

The single line diagram of the grid is given in Fig. 3. In this figure, $\mathrm{L}_{1}, \mathrm{~L}_{2}$ and $\mathrm{L}_{3}$ are three $200 \mathrm{~m}$ long sections of a $600 \mathrm{~m}$ distribution feeder line. The specifications of the cable used in the LV network are given in Table 1.

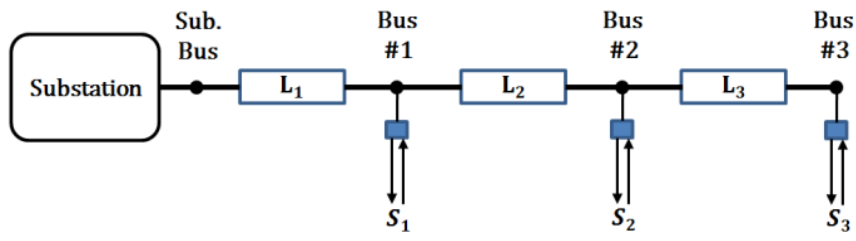

Fig. 3. Single line diagram of the studied grid

In Fig. 3, the load points are shown with bidirectional 
arrows to emphasize the presence of PV panels in the real studied grid. Accordingly, the meters in the grid measure the summation of the absorbed power by the load and the generated power by the PV panels. Hence there are negative and positive values in power profiles, especially in spring and summer.

Table 1. Specification of copper cables of the LV network

\begin{tabular}{|c|c|c|c|}
\hline $\begin{array}{c}\text { Nominal section } \\
\left(\mathrm{mm}^{2}\right)\end{array}$ & $\begin{array}{c}\mathrm{R} \\
(\mathrm{m} \Omega / \mathrm{m})\end{array}$ & $\begin{array}{c}\mathrm{X} \\
(\mathrm{m} \Omega / \mathrm{m})\end{array}$ & $\begin{array}{c}\text { Current carrying capacity } \\
(\mathrm{A})\end{array}$ \\
\hline 185 & 0.123 & 0.0908 & 545 \\
\hline
\end{tabular}

The active power of the substation in Fig. 4, the power factor in Fig. 5 and the voltage at the output of $\mathrm{MV} / \mathrm{LV}$ substation transformer in Fig. 6 are given for April $1^{\text {st }}$ as the sample day.

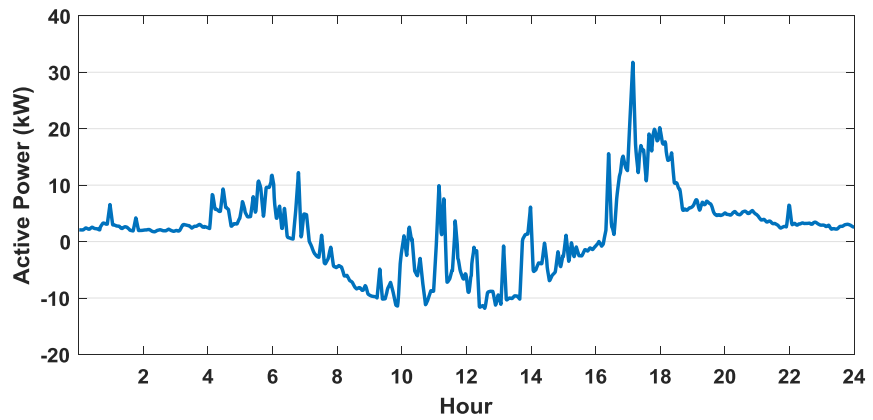

Fig. 4. Active power curve of the substation on April $1^{\text {st }}$

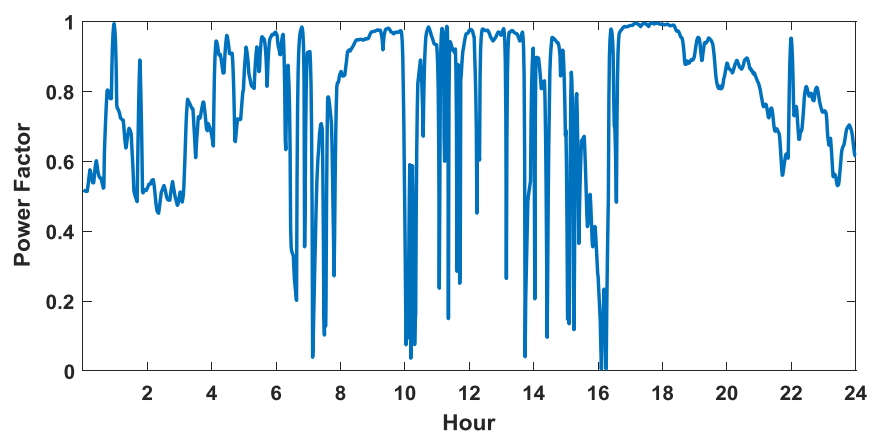

Fig. 5. Power factor of the substation on April $1^{\text {st }}$

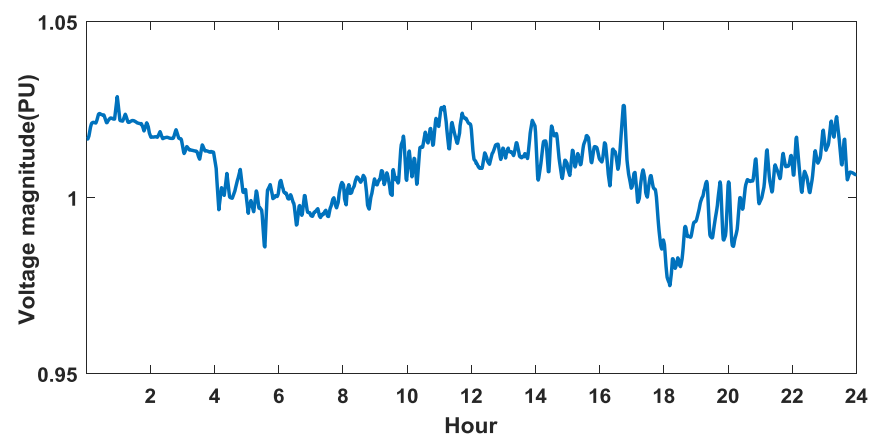

Fig. 6. Voltage at the output of MV/LV transformer on April $1^{\text {st }}$

The effect of the PV generation in the grid can be seen in daytime hours in Fig. 4. It is clear that the absolute value of measured active power is quite low due to the presence of PV generation in the grid. Hence, it can be seen in Fig. 5 that the power factor in the grid is often very low during the daytime.

According to Fig. 6, the voltage at the output of MV/LV transformer which is the substation voltage of the $\mathrm{LV}$ grid is close to the nominal value during the whole day. In order to determine the grid specification more precisely, the voltage assessment is accomplished in the whole year and a brief review to the results is given as distribution curves in pu in Fig. 7. Moreover, studying the voltage of all buses given in Fig. 7 as a single Gaussian curve, the variance is equal to $29 \times 10^{-5}$. From a voltage constraint point of view, according to the results given in Fig. 7, the voltage magnitude of all buses during the whole year is between $210.34 \mathrm{~V}$ and $247.39 \mathrm{~V}$, which means that the voltage deviation has never crossed the $10 \%$ limit. Therefore, this network, with $184.34 \mathrm{kWh}$ energy loss during the whole year and the specified voltage deviation range can be considered as a very good network.

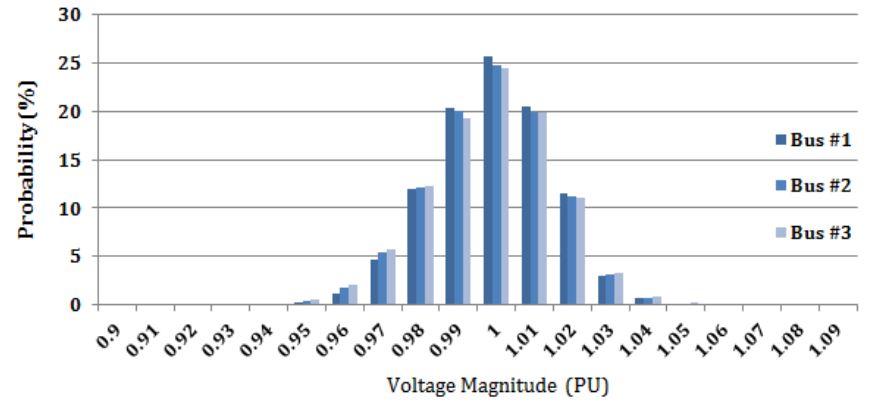

Fig. 7. Voltage magnitude distribution curve for different buses in the main grid during the whole year

In the future, there would be more requests to connect new loads or DG units to the grid. Therefore, even if there is no problem in voltage characteristics of a network, there is the trend by the DSOs to see if it is possible to find strategies to reduce the voltage deviations and permit additional load connections without infrastructure investments in the network. Hence, it is important to understand what happens when the voltage is stabilized in the substation and is considered constant during the year. Such a result can be obtained by adding a SPEC to the grid. But, once again, it is important to take the limitations into account to understand whether the device can provide the voltage in the substation or not.

\section{GRID ASSESSMENT IN PRESENCE OF THE SPEC}

In this Section, the described SPEC is added to the substation bus and the voltage of substation is considered to be constant during the whole year. Accordingly, the voltage assessment is accomplished in the grid in the presence of the device and the results are compared with the main grid.

\section{A. The effect of SPEC on the grid}

In order to accomplish the assessment with different SPEC settings, three voltage set-points are considered in the study of this section. The grid specifications in the presence of the SPEC for all the settings are given separately in following subsections.

\section{1) Normal set-point for $\operatorname{SPEC}\left(V_{P C C, \text { ref }}=1.00 \mathrm{pu}\right)$}

As the primary assessment, the SPEC is added with 
normal set-point $\left(V_{P C C, r e f}=1.0\right)$ and the voltage of the substation bus is considered to be fixed on $230 \mathrm{~V}$ during the whole year. The voltage magnitude distribution curve of the grid is given for the scenario in Fig. 8. As shown in Fig. 8, the voltage magnitude of all buses are between $0.99 \mathrm{pu}$ and $1 \mathrm{pu}$ in about $70 \%$ of the whole year which means that the stabilization is successfully accomplished. Moreover, the variance of the Gaussian curve for the voltage values in all buses is decreased to $2.6 \times 10^{-5} \mathrm{pu}$.

The minimum and maximum voltage magnitude of the grid during the whole year among all buses is $221.36 \mathrm{~V}$ and $234.29 \mathrm{~V}$ respectively. Accordingly, the voltage magnitude in all buses of the grid is between $0.95 \mathrm{pu}$ and $1.05 \mathrm{pu}$ in the presence of the SPEC in the whole year. The grid loss is almost equal with the main grid and it is $183.75 \mathrm{kWh}$ in the year.

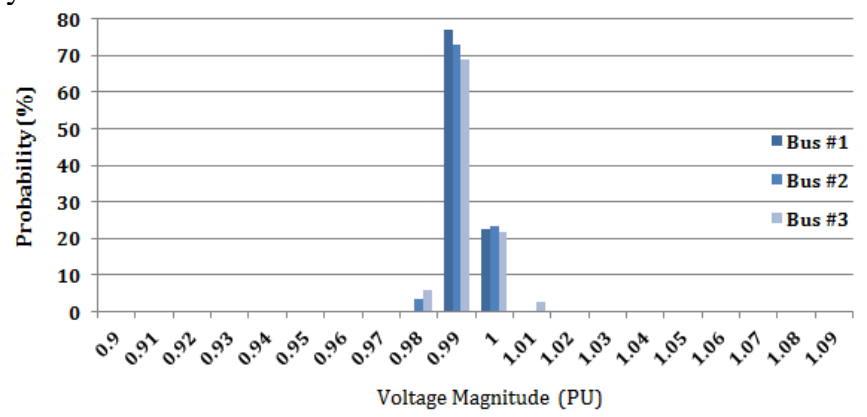

Fig. 8. Voltage magnitude distribution curve in the presence of SPEC with $V_{P C C, \text { ref }}=1.00 \mathrm{pu}$ during the whole year

\section{2) SPEC voltage set-point increase $\left(V_{P C C, \text { ref }}=1.03 \mathrm{pu}\right)$}

The voltage set-point of the SPEC is 3\% increased and the effect of the adjustment is monitored during the whole year. The voltage distribution curve is given in Fig. 9. The minimum and maximum voltage of the grid is changed to $228.54 \mathrm{~V}$ and $241.07 \mathrm{~V}$ with a variance of $2.5 \times 10^{-5} \mathrm{pu}$ for the voltage of all load buses and the total loss is decreased significantly to $173.07 \mathrm{~kW}$.

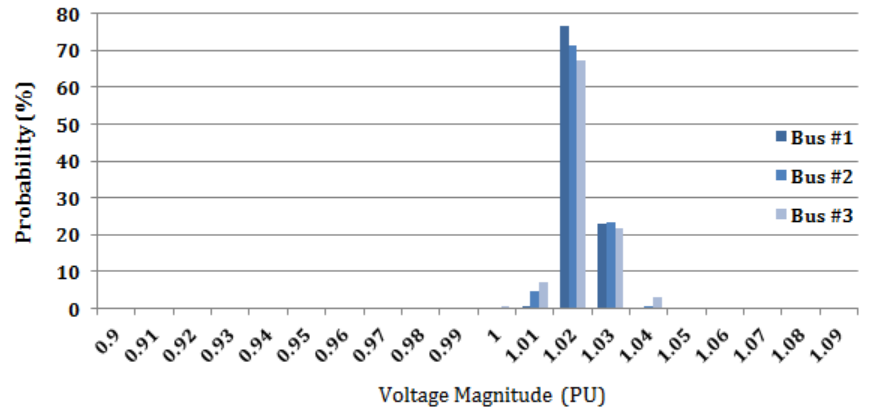

Fig. 9. Voltage magnitude distribution curve in the presence of SPEC with $V_{P C C, \text { ref }}=1.03$ pu during the whole year

\section{3) SPEC voltage set-point decrease $\left(V_{P C C, r e f}=0.97 \mathrm{pu}\right)$}

As the final scenario, the voltage set-point is $3 \%$ decreased and the whole-year voltage assessment is accomplished for the new setting. The voltage distribution curve is given for this case in Fig. 10. The minimum and maximum voltage of the grid are $214.17 \mathrm{~V}$ and $227.52 \mathrm{~V}$ while the variance is equal with $2.6 \times 10^{-5} \mathrm{pu}$ for the voltage of all buses. It should be noted that in this case, the grid total loss in the whole year is increased to $195.47 \mathrm{kWh}$.

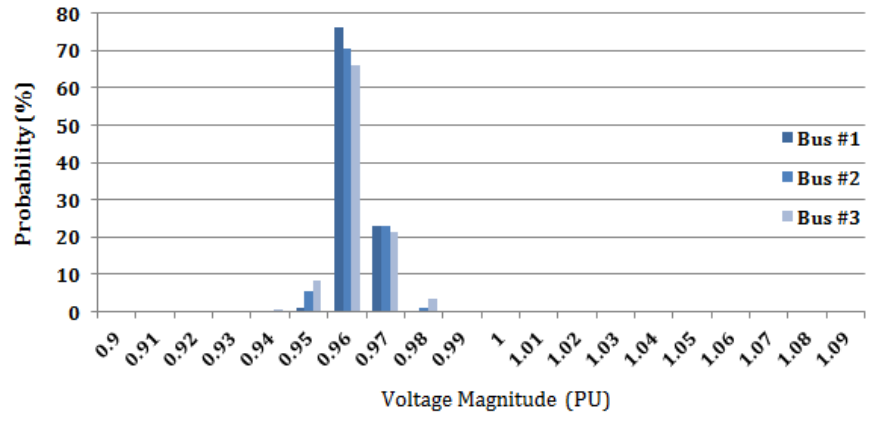

Fig. 10. Voltage magnitude distribution curve in the presence of SPEC with $V_{P C C, \text { ref }}=0.97 \mathrm{pu}$ during the whole year

\section{B. Capability assessment and result conclusion}

As a summary of the assessments, the voltage magnitude distribution curve of the whole grid during the whole year is compared in the form of the Gaussian curve for the different cases in Fig. 11. It should be noted that the Gaussian curves are demonstrated with respect to the voltage magnitude of all buses in the grid. The reduction of voltage variation using SPEC is clear in the results. As described before, the voltage variance of the whole grid is more than $90 \%$ decreased in the presence of the device. Moreover, the other important effect of the SPEC is the ability of moving the voltage distribution curve which is shown in Fig. 11 and it is accomplished using the SPEC set-point.

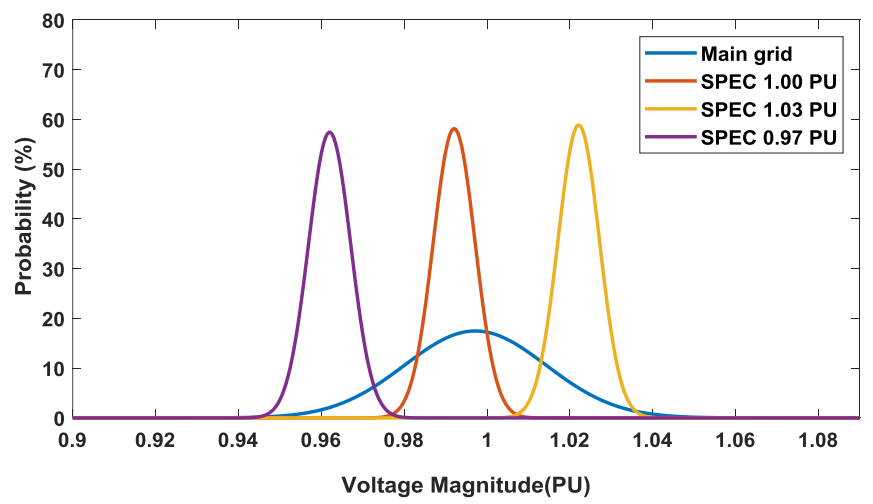

Fig. 11. Comparison of voltage magnitude distribution curve of the whole grid for different analyzed scenarios

As the final assessment, the ability of the SPEC for providing the constant voltage in the substation is carried out with respect to the data given in [16]. Accordingly, the maximum compensation capability of the SPEC is considered to be $60 \%$ of the nominal voltage and the results are given in Table 2. According to the results, with nominal voltage set-point, the SPEC can provide constant voltage in the substation for $93.3 \%$ of the time during the year. If the set-point increases $3 \%$, the SPEC functionality is highly affected and the device can only provide the desired voltage at the substation in $79.8 \%$ of the time. In these cases, the device needs extra reactive power from the grid. If the reactive power is not provided, the voltage set-point of the SPEC should be readjusted using the methods of previously published papers [12]. 
Table 2. Capability analysis of SPEC with different set-points

\begin{tabular}{|c|c|c|c|}
\hline Scenario & $\begin{array}{c}V_{P C C, \text { ref }} \\
=1.00 \mathrm{pu}\end{array}$ & $\begin{array}{c}V_{P C C, \text { ref }} \\
=1.03 \mathrm{pu}\end{array}$ & $\begin{array}{c}V_{P C C, \text { ref }} \\
=0.97 \mathrm{pu}\end{array}$ \\
\hline $\begin{array}{c}\text { Fixed-voltage providing capability } \\
\text { (\% of the time in the whole year) }\end{array}$ & 93.3 & 79.8 & 99.7 \\
\hline $\begin{array}{c}\text { Maximum voltage } \\
(\mathrm{pu})\end{array}$ & 1.019 & 1.048 & 0.989 \\
\hline $\begin{array}{c}\text { Minimum voltage } \\
(\mathrm{pu})\end{array}$ & 0.962 & 0.994 & 0.931 \\
\hline
\end{tabular}

On the other hand, by decreasing the voltage set-point, the device can provide $0.97 \mathrm{pu}$ voltage magnitude in the substation in $99.7 \%$ of the time during the year. Although the grid loss is a little increased in this case, the voltage variance is decreased from $2.9 \times 10^{-4}$ in the main grid to $2.6 \times 10^{-5}$ which is a considerable improvement. The main problem, in this case, is the lower value of minimum voltage in the grid comparing to the other cases. In order to resolve the problem, an increment in the tap of the substation transformer can be implemented. Accordingly, by support through the tap changer, the device can provide the desired voltage in the grid in the whole year without any support by the grid.

\section{CONCLUSION}

In this paper, the effect of SPEC on the voltage profile of an LV network is investigated. In order to accomplish the assessment in a realistic condition, the study is applied to a real network with real data of meters. Accordingly, the voltage assessment is primarily accomplished on the main network for the whole year. In the next step, the SPEC is added to the grid to fix the voltage in the substation and the voltage assessment is repeated in the presence of the device. For further assessment, the voltage set-point of the SPEC is changed to higher and lower values and the grid voltage is also monitored in the presence of the device with new settings. Finally, the ability of the SPEC for maintaining the substation voltage on the desired value is analyzed. According to the results, the device is capable of providing the constant voltage in the substation for $93.3 \%$ and $79.8 \%$ of the time during the whole year if the set-points are selected to be $1.00 \mathrm{pu}$ and $1.03 \mathrm{pu}$, respectively. For the rest of the time, the device needs excessive reactive power from the grid. On the other hand, according to the results, the device is capable for maintaining the voltage within the specified value for $99.7 \%$ of the time during the whole year if the set-point is selected to be $0.97 \mathrm{pu}$. In this case, the decrement in voltage magnitude of the buses in the grid can be compensated by increasing the voltage in the substation. Accordingly, the voltage improvement can be provided using the SPEC without any reactive support from the grid.

\section{REFERENCES}

[1]

[4]
P.-C. Chen, R. Salcedo, Q. Zhu, F. De Leon, D. Czarkowski, Z.-P. Jiang, V. Spitsa, Z. Zabar, R.E. Uosef, Analysis of voltage profile problems due to the penetration of distributed generation in lowvoltage secondary distribution networks, IEEE Trans. Power Deliv. 27 (2012) 2020-2028.

R. Faranda, H. Hafezi, S. Leva, M. Mussetta, E. Ogliari, The optimum PV plant for a given solar DC/AC converter, Energies. 8 (2015) 4853-4870.

I. El-Samahy, E. El-Saadany, The effect of DG on power quality in a deregulated environment, in: IEEE Power Eng. Soc. Gen. Meet. 2005, IEEE, 2005: pp. 2969-2976.

E. Kazemi-Robati, M.S. Sepasian, Passive harmonic filter planning considering daily load variations and distribution system reconfiguration, Electr. Power Syst. Res. 166 (2019) 125-135.

B.A. Robbins, A.D. Domínguez-García, Optimal Reactive Power Dispatch for Voltage Regulation in Unbalanced Distribution Systems, IEEE Trans. Power Syst. 31 (2016) 2903-2913. doi:10.1109/TPWRS.2015.2451519.

S.A. González, M.I. Valla, UPQC implemented with Cascade Asymmetric Multilevel Converters, Electr. Power Syst. Res. 124 (2015) 144-151.

J. Ye, H.B. Gooi, F. Wu, Optimization of the Size of UPQC System Based on Data-Driven Control Design, IEEE Trans. Smart Grid. 9 (2018) 2999-3008.

G. D'Antona, D. Della Giustina, R. Faranda, H. Hafezi, Open UPQC power quality manager within distributed generation systems, in: Diagnostics Electr. Mach. Power Electron. Drives (SDEMPED), 2015 IEEE 10th Int. Symp., IEEE, 2015: pp. 501507.

H. Hafezi, G. D’Antona, A. Dedè, D. Della Giustina, R. Faranda, G. Massa, Power quality conditioning in LV distribution networks: Results by field demonstration, IEEE Trans. Smart Grid. 8 (2017) 418-427.

G. D’Antona, R. Faranda, H. Hafezi, G. Accetta, D. Della Giustina, Open UPQC: A possible solution for power quality. Series unit analysis, in: 2014 Int. Symp. Power Electron. Electr. Drives, Autom. Motion, 2014: pp. 1104-1109.

H. Hafezi, R. Faranda, C. Gandolfi, R. Chiumeo, Investigation on different control methods for single-phase DVC, in: Harmon. Qual. Power (ICHQP), 2018 18th Int. Conf., IEEE, 2018: pp. 1-6.

H. Hafezi, R. Faranda, Dynamic Voltage Conditioner: A New Concept for Smart Low-Voltage Distribution Systems, IEEE Trans. Power Electron. 33 (2018) 7582-7590.

A.M. Rauf, V. Khadkikar, An Enhanced Voltage Sag Compensation Scheme for Dynamic Voltage Restorer, IEEE Trans. Ind. Electron. 62 (2015) 2683-2692.

T. Jimichi, H. Fujita, H. Akagi, Design and experimentation of a dynamic voltage restorer capable of significantly reducing an energy-storage element, IEEE Trans. Ind. Appl. 44 (2008) 817825.

E. Babaei, M.F. Kangarlu, M. Sabahi, Compensation of voltage disturbances in distribution systems using single-phase dynamic voltage restorer, Electr. Power Syst. Res. 80 (2010) 1413-1420.

M. Brenna, R. Faranda, E. Tironi, A new proposal for power quality and custom power improvement: OPEN UPQC, IEEE Trans. Power Deliv. 24 (2009) 2107-2116. 